\title{
Compact Dual-Band Coupler for Vehicular Beam-Forming Array
}

\author{
Dakui Wu and Guoxin Zheng \\ Key Laboratory of Specialty Fiber Optics and Optical Access Networks, Shanghai University, Shanghai 200072, China \\ Correspondence should be addressed to Dakui Wu; heartcom@163.com
}

Received 6 October 2016; Revised 5 December 2016; Accepted 19 December 2016; Published 18 January 2017

Academic Editor: N. Nasimuddin

Copyright (C) 2017 Dakui Wu and Guoxin Zheng. This is an open access article distributed under the Creative Commons Attribution License, which permits unrestricted use, distribution, and reproduction in any medium, provided the original work is properly cited.

\begin{abstract}
A novel kind of compact dual-band quadrature patch coupler for vehicular beam-forming array is proposed for the first time in this paper. To keep the performance of the first operating frequency $2.4 \mathrm{GHz}$ (for Bluetooth Low Energy (BLE)) and generate the second operating frequency $5.9 \mathrm{GHz}$ (for Dedicated Short Range Communications (DSRC)) simultaneously, complementary triangular split resonant rings (CTSRRs) and splitting gaps are employed to improve the performance of this new coupler; final size of the proposed coupler is $0.24 \lambda_{g}$ (for $2.4 \mathrm{GHz}$ ). To validate the performance and design method of the coupler this paper proposed, a 3D model is constructed and optimized with ANSOFT HFSS firstly and then a coupler prototype is fabricated and measured. The measured results show that the amplitude unbalance $(\mathrm{AU})$ is $0.54 \mathrm{~dB}$ and $0.44 \mathrm{~dB}$ for $2.4 \mathrm{GHz}$ and $5.9 \mathrm{GHz}$, respectively, and the corresponding phase unbalance (PU) is 93.5 and 92 degrees, respectively.
\end{abstract}

\section{Introduction}

The development of autonomous driving brings new challenge to vehicular communication; Dedicated Short Range Communication (DSRC) is a very potential technology for the emerging market of intelligent transport system (ITS); DSRC system is fixed on $5.9 \mathrm{GHz}$ with $75 \mathrm{MHz}$ of spectrum in US, which is mainly used for V2I (vehicle to infrastructure) communication. On the other side, Bluetooth devices are more and more widely used in new vehicles for scenarios like V2V (vehicle-to-vehicle) communication and communication between different on-board terminals. Currently, omnidirectional or wide beam antenna is used for DSRC or Bluetooth terminal [1-3], whereas these terminals will consume more power for its antenna's poor gain performance especially in long-distance V2X scenarios. In these cases, beam-switching array could be a better choice for DSRC or Bluetooth terminals.

Beam-switching array based on butler-matrix is characterized with fast-switching, low-cost, simple structure, and easy integrating. Butler-matrix feeding network is the key component for this kind of array and butler-matrix which is composed of quadrature couplers is widely used as feeding network $[4,5]$. Comparing with traditional branch line coupler, patch coupler is characterized with compact size and flexible structure. Some patch couplers with dualband performance were proposed in former paper [6-9]; Table 1 shows the differences between previous works and this work in terms of size, complexity, shapes, amplitude unbalance (AU), and phase unbalance (PU). In [6], dualband performance is realized by adding extra resonant patch on rectangular coupler, which will result in bulk size; the same problem exists in [7] which employs extra branch to realize dual-band performance; in [8], due to the limited size of square complementary split ring resonators (SCSRRs) which etched in circular patch, dual-band operating performance cannot be realized for the desired frequency ratio of $5.8 \mathrm{GHz} / 2.4 \mathrm{GHz}$; the same problem exists in [9] which uses embedded spiral open stubs to generate the second frequency of $1.385 \mathrm{GHz}$; the maxim frequency ratio is restricted by size of the etched circular hole. In this paper, a new kind of dualband patch coupler which employs square patch and triangle split resonant rings (CTSRRs) is proposed for butler-matrix based beam-switching array; the performance of the coupler is validated by simulated and measured results.

\section{Structure of the Coupler}

As shown in Figure 1, the proposed patch coupler is composed of traditional diagonal slot loaded patch coupler [10] and 
TABLE 1: Performances of different dual-band patch coupler.

\begin{tabular}{lccccc}
\hline Operating freq. (GHz)/Ref. number & Size in $\lambda_{g}$ & Complexity & Shape & AU (dB) & PU (degree) \\
\hline $2.4 \&$ 5.8/Ref. [6] & $1.07 \lambda_{g} \times 0.66 \lambda_{g}$ & Middle & Hybrid rectangular patch & 0.1 & 3.1 \\
0.915 \& 1.575/Ref. [7] & $0.3 \lambda_{g} \times 0.3 \lambda_{g}$ & Middle & Rectangular patch with stub and etched holes & 0.5 & 3 \\
$3 \& 5$ /Ref. [8] & $0.57 \lambda_{g} \times 0.3 \lambda_{g}$ & High & Circular patch with ring resonator & 0.7 & 6.7 \\
0.985 \& 1.385/Ref. [9] & $0.22 \lambda_{g} \times 0.22 \lambda_{g}$ & High & Rectangular patch with spiral open stubs & 0.6 & 3 \\
$2.4 \&$ 5.8/this work & $0.24 \lambda_{g} \times 0.24 \lambda_{g}$ & High & Rectangular patch with triangular resonator & 0.5 & 3.5 \\
\hline
\end{tabular}

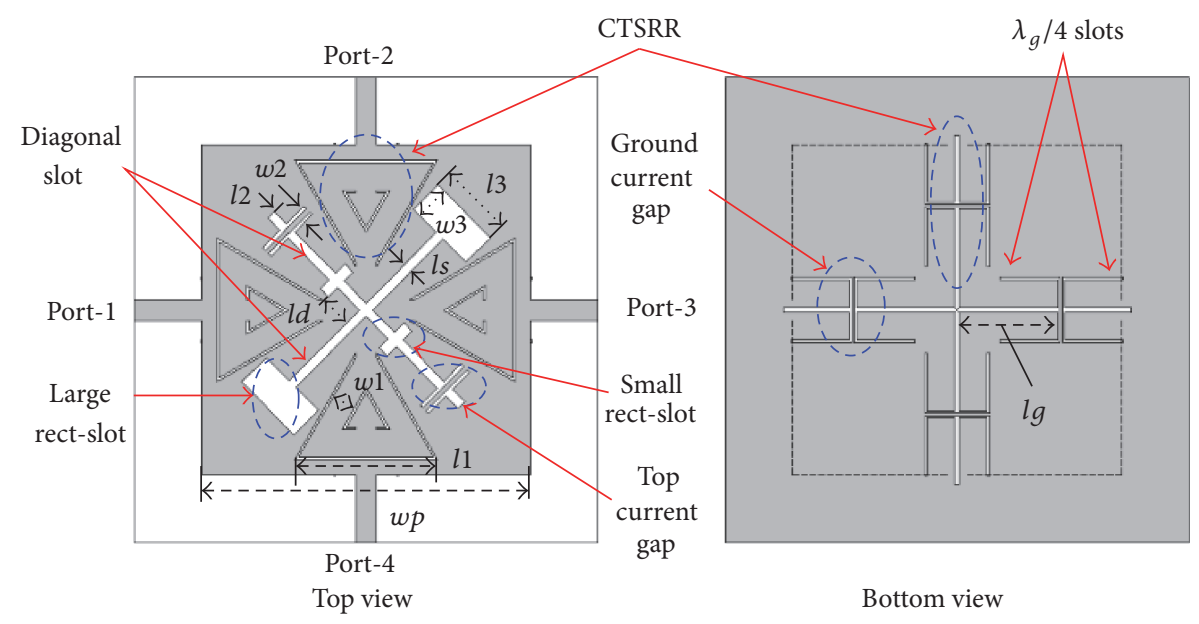

FIGURE 1: Top and bottom view of the proposed patch coupler.

four CTSRRs [11, 12]; two symmetry wide rectangular slots are employed as perturbation elements to degrade patch resonator's geometrical symmetry $[10,13]$. To generate the second resonant frequency of $5.9 \mathrm{GHz}$, four similar CTSRRs are etched on space area between two adjacent slots; the space area can be used sufficiently for its special shape of the CTSRR. At the same time, the patch current distribution almost keeps unchanged for most of the current concentrated along the crossed slots [9]. To improve the amplitude balance of the two output ports at $5.9 \mathrm{GHz}$, another two small symmetry rectangular slots are loaded on the other diagonal slot, and a current gap is constructed to furthermore adjust the amplitude balance of $2.4 \mathrm{GHz}$ on top side of the patch. The new appearing slots of four CTSRRs on ground split the whole ground into four parts; the current distribution will be totally different from that of traditional coupler with a whole ground, and this will lead to frequency shift for $2.4 \mathrm{GHz}$ operating frequency, so a current gap which is composed of two $\lambda_{g} / 4$ branches is introduced to shorten the current path of the ground.

\section{Analysis}

The equivalent circuit of CTSRR can be seen as dual of the Triangular Split Ring Resonator (TSRR) [12], which is shown in Figure 2. The inductance $(L)$ and capacitance $\left(C_{s}\right)$ of the CTSRR are calculated by applying Babinet's principle to the TSRR elements [12]. The operating frequency of CTSRR

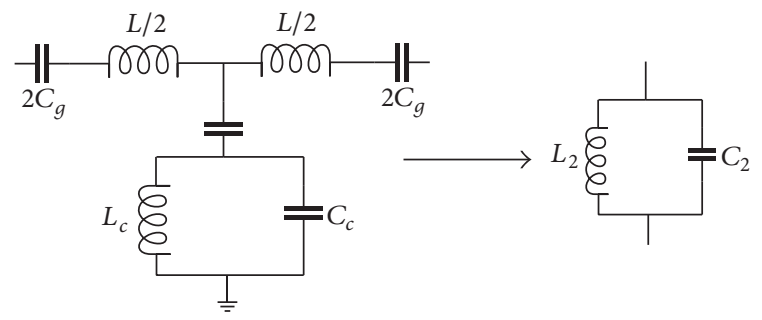

FIGURE 2: Equivalent circuit of CTSRR and its simplified form.

is mainly influenced by the opening size $w 1$ and length of resonator $l 1$, which can be expressed as follows [12]:

$$
f_{0}=\frac{1}{2 \pi \sqrt{L C_{s}}}
$$

where

$$
\begin{aligned}
C_{s} & =0.75 S_{\mathrm{avg}} C_{\mathrm{pul}}, \\
L & =3 \frac{\mu_{0} \mu_{r}}{2 \pi}\left(\ln \left(\frac{S_{\mathrm{avg}}}{w}\right)-1.405\right) .
\end{aligned}
$$

$S_{\text {avg }}$ is the average length of the side of the triangles and $C_{\text {pul }}$ is the capacitance per unit length between the triangles [9], the calculated results of above parameters are shown in Table 2. On the other hand, the simplified form of this equivalent is extracted by circuit theory to show the overall circuit with 


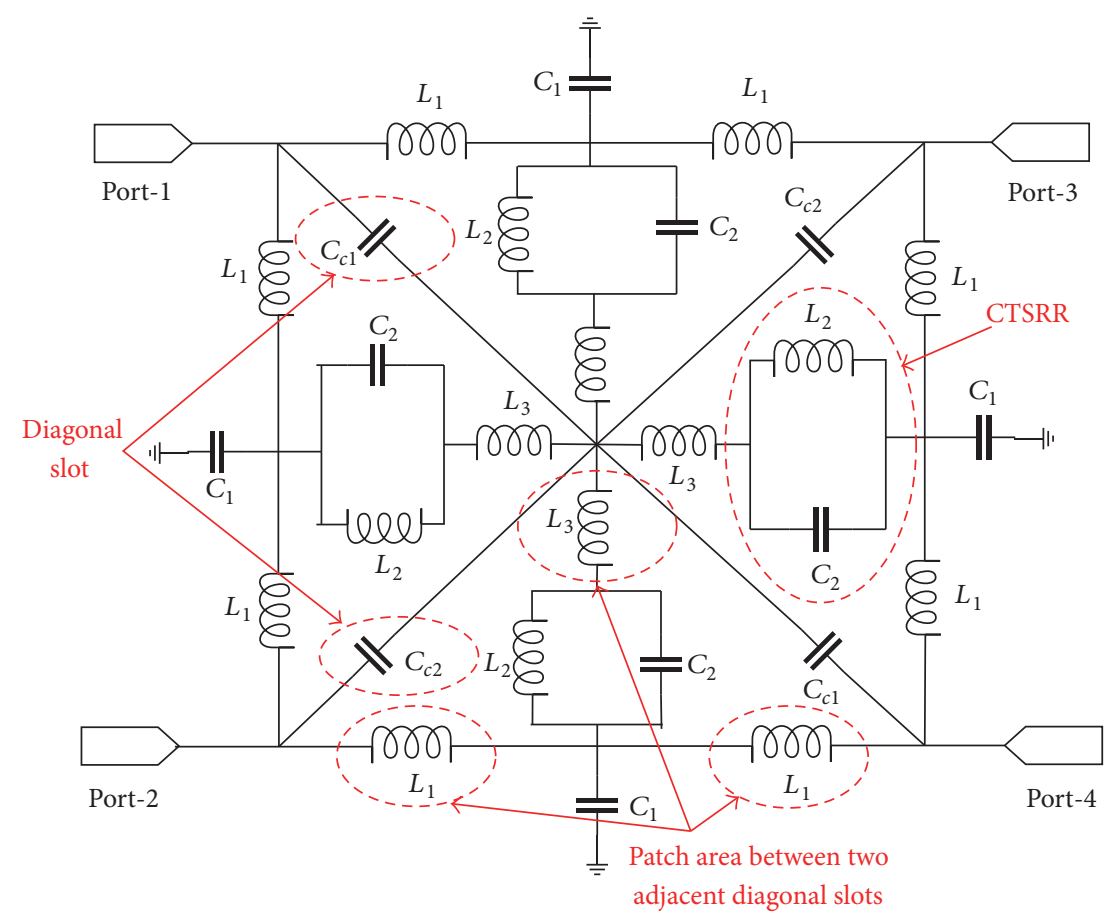

FIGURE 3: Equivalent circuit of the dual-band coupler.

TABLE 2: Parameters of the CTSRR equivalent circuit.

\begin{tabular}{lc}
\hline Parameters & Results \\
\hline$C_{s}$ & $5.27 \times 10^{-16} / f_{0}=2.4 \mathrm{GHz} ; 8.71 \times 10^{-17} / f_{0}=5.9 \mathrm{GHz}$ \\
$C_{\text {pul }}$ & $1.78 \times 10^{-16} / f_{0}=2.4 \mathrm{GHz} ; 2.94 \times 10^{-17} / f_{0}=5.9 \mathrm{GHz}$ \\
$S_{\text {avg }}$ & $3.95 \mathrm{~mm}$ \\
$L$ & $8.36 \times 10^{-7} \mathrm{H}$ \\
\hline
\end{tabular}

a compact way, which is also shown in Figure 2. So the equivalent circuit of the patch coupler this paper proposed can be expressed as Figure 3 ; the parameters $C_{c 1}$ and $C_{c 2}$ represent the capacitance which is generated by diagonal gap between two adjacent CTSRRs.

\section{Validation}

As mentioned above, the CTSRR is used to generate the second resonant frequency of $5.9 \mathrm{GHz}$ and prolong the current path of $2.4 \mathrm{GHz}$ simultaneously; this can be proved by current distribution of the patch coupler. A 3D model of the coupler is constructed and optimized by ANSOFT HFSS to validate the performance and design method; the current distributions of $2.4 \mathrm{GHz}$ and $5.9 \mathrm{GHz}$ are shown in Figures 4 and 5, respectively; we can see from Figure 4 that the current distribution does not change after the CTSRR was introduced into the patch. Whereas the current distribution of CTSRR for $5.9 \mathrm{GHz}$ is obviously changed, most of current is centred on the triangular gap, which proves that the dominant resonant frequency of $5.9 \mathrm{GHz}$ is generated by CTSRR successfully.

To furthermore validate the performance and design method of this compact dual-band patch coupler, a coupler
TABLE 3: Final optimized results of the prototype.

\begin{tabular}{lc}
\hline Parameters & Dimension $(\mathrm{mm})$ \\
\hline$w p$ & 14.2 \\
$l d$ & 1.35 \\
$l s$ & 0.4 \\
$l g$ & 4.25 \\
$l 1$ & 6.2 \\
$w 1$ & 1 \\
$l 2$ & 1.25 \\
$w 2$ & 0.5 \\
$l 3$ & 3.2 \\
$w 3$ & 1.5 \\
\hline
\end{tabular}

prototype is simulated, fabricated, and measured to compare with the simulation results. Initial length of the diagonal slot is set as the length of the patch length $w p$ and the final optimized result is $12 \mathrm{~mm}$; the length and width of the small rectangular slot are $1.5 \mathrm{~mm}$ and $0.5 \mathrm{~mm}$; the corresponding location $l d=1.35 ; l 2$ and $w 2$ represent the location and width of the top current gap. The widths of slot both on top and bottom sides are $0.1 \mathrm{~mm} ; \lambda_{g}$ is the guided wavelength of $5.9 \mathrm{GHz}$; other parameters in Figures 1 and 3 are shown in Table 3. The coupler prototype is shown in Figure 6; FR4 substrate with a thickness of $20 \mathrm{mil}$ is used to fabricate this prototype.

The simulated and measured S11 and S41 are shown in Figure 7, including the simulation results of CKT model of Figure 3; we can see that S11 and S41 both perform well in the two interested bands of $2.4 \mathrm{GHz}$ and $5.9 \mathrm{GHz}$ for all the 


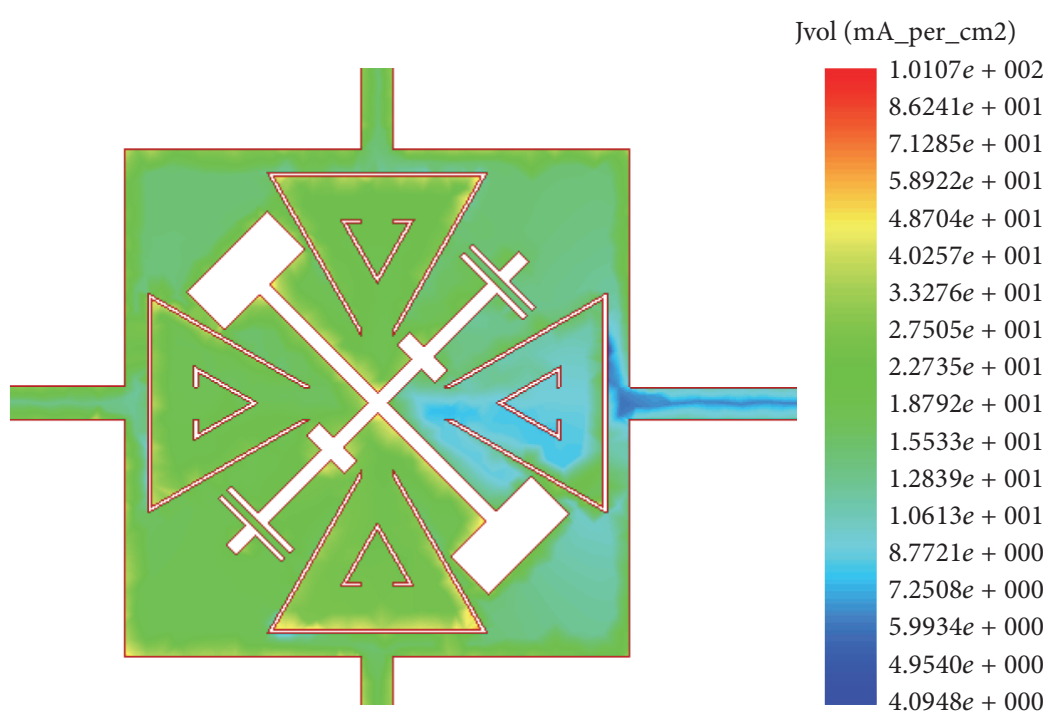

FIgURE 4: Current distribution of the coupler for $2.4 \mathrm{GHz}$.
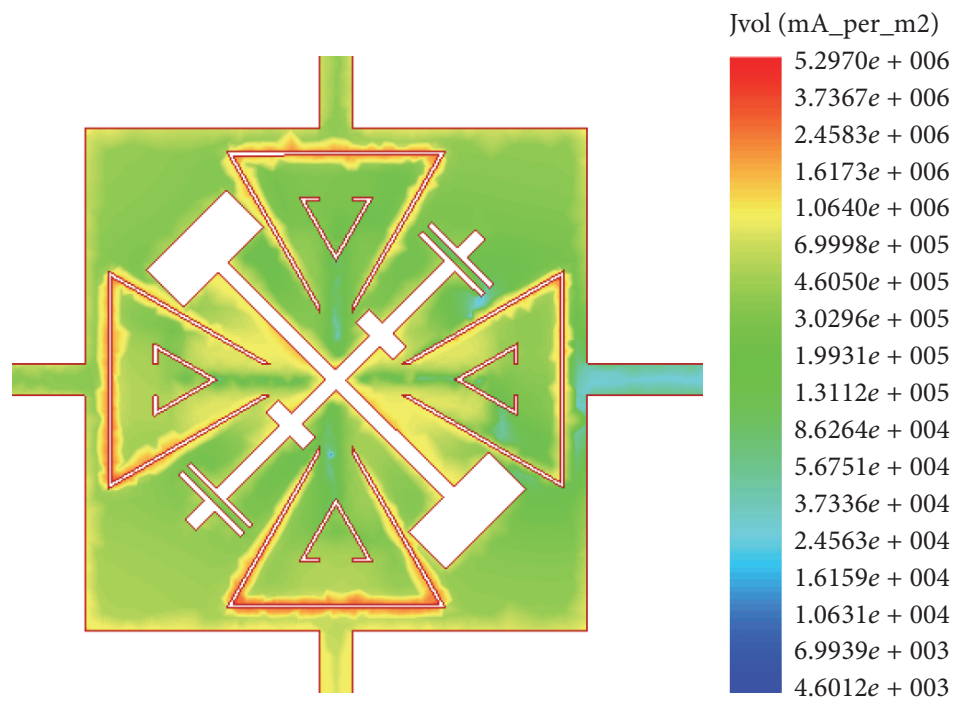

FIgURE 5: Current distribution of the coupler for $5.9 \mathrm{GHz}$.

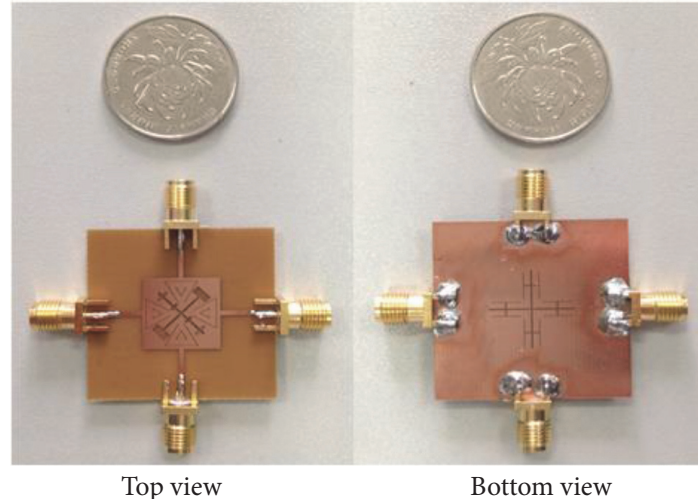

Figure 6: Prototype of the dual-band patch coupler. three sets of data; the measured S11 is about $-11 \mathrm{~dB}$ and $-10 \mathrm{~dB}$ for $2.4 \mathrm{GHz}$ and $5.9 \mathrm{GHz}$, respectively. CKT model simulation results show that the operating frequency band of CKT model meets well with simulation and measured results of $3 \mathrm{D}$ model. Figure 8 shows the corresponding results of S21 and S31; we can see that all three sets of results meet well with each other; the measured transmission coefficients S21 and S31 are $-5.2 \mathrm{~dB}$ and $-5.7 \mathrm{~dB}$ for $2.4 \mathrm{GHz}$ and $-4.7 \mathrm{~dB}$ and $-4.6 \mathrm{~dB}$ for $5.9 \mathrm{GHz}$. Figure 9 is the simulated and measured results of the phase response of the coupler porotype. AU and PU of the coupler prototype are shown in Figure 10; the simulated AU is $0.4 \mathrm{~dB}$ at $2.4 \mathrm{GHz}$ and $0.8 \mathrm{~dB}$ at $5.9 \mathrm{GHz}$; the corresponding measured results are $0.5 \mathrm{~dB}$ and $0.4 \mathrm{~dB}$, respectively. The simulated PU are 93.5 degrees and 92 degrees for $2.4 \mathrm{GHz}$ and $5.9 \mathrm{GHz}$, respectively; the corresponding measured results are 


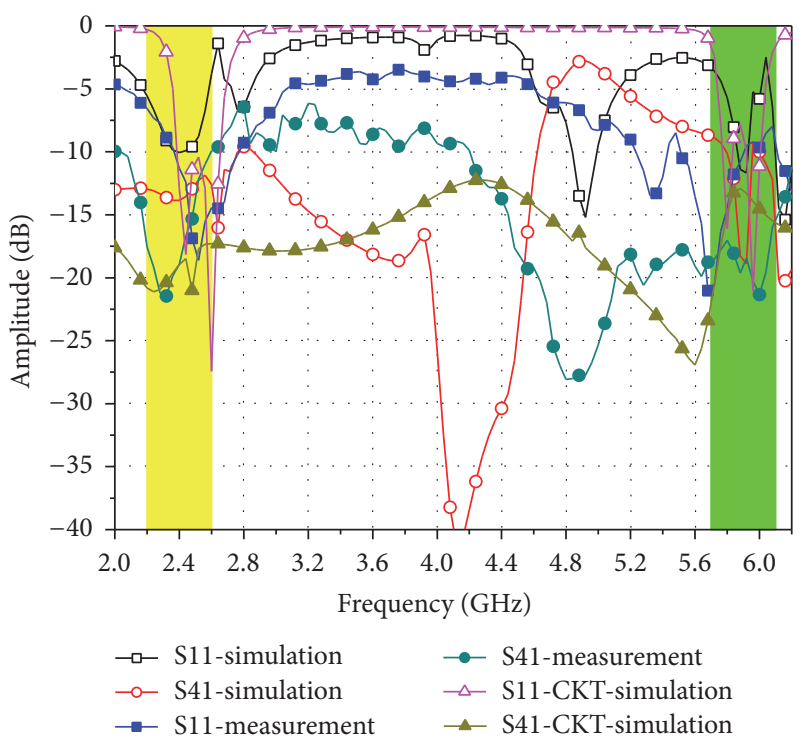

FIGURE 7: S11 and S41 of the coupler prototype and CKT model.

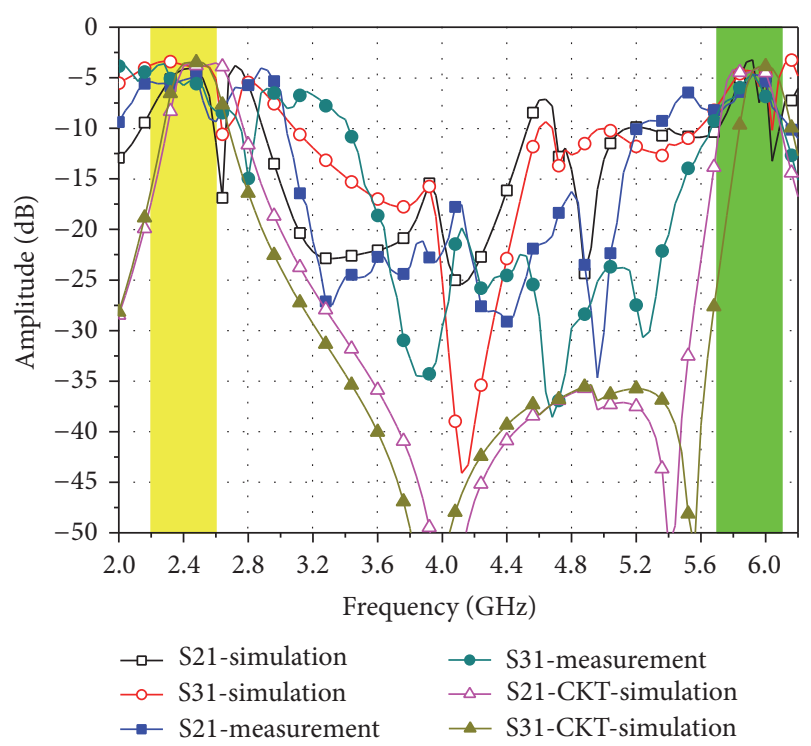

FIGURE 8: S21 and S31 of the coupler prototype and CKT model.

91 degrees and 93 degrees. The above differences between simulated and measured results come from fabrication tolerance and measurement errors. So the performance and design method of this compact dual-band patch coupler proposed in this paper are validated.

\section{Conclusion}

A novel dual-band compact patch coupler for butler-matrix beam-forming array is proposed in this paper; to get the second operating frequency of $5.9 \mathrm{GHz}$, CTSRRs (complementary triangular split resonant rings) are employed to avoid influencing another operating frequency of $2.4 \mathrm{GHz}$. Performance and design method of this coupler are validated

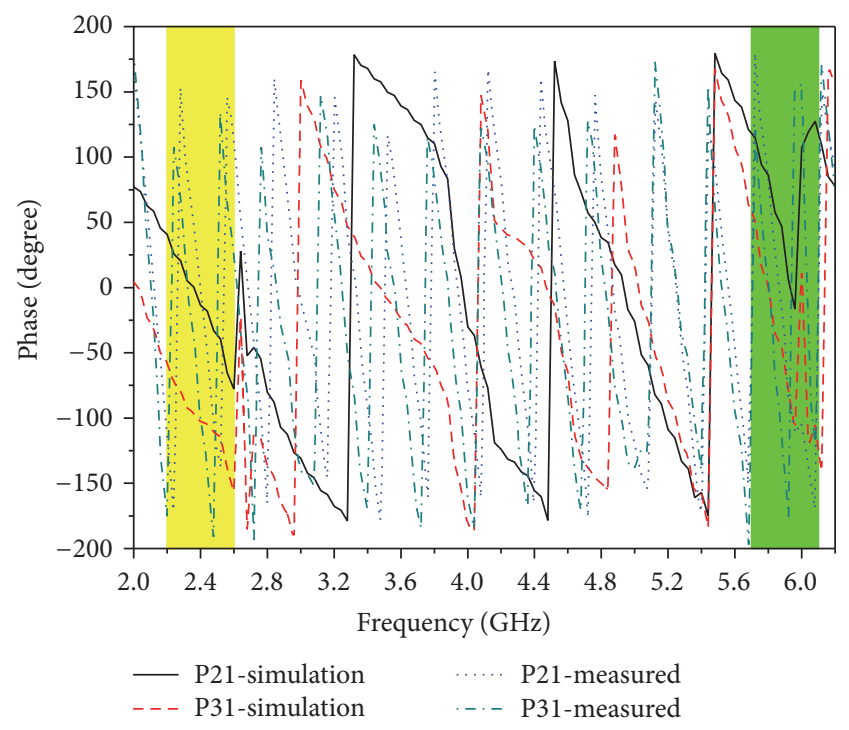

FIGURE 9: Phase response of the coupler prototype.

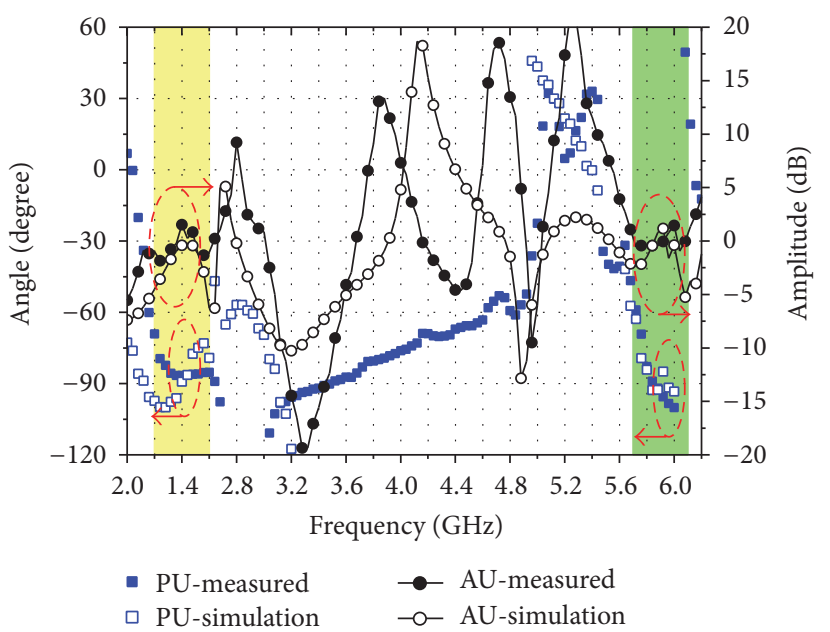

FIGURE 10: Amplitude and phase unbalance of the coupler prototype.

by simulation and measured results. This compact coupler can be used in vehicular beam-forming array and other wireless communication systems, which is operating in $2.4 \mathrm{GHz}$ and/or $5.9 \mathrm{GHz}$.

\section{Competing Interests}

The authors declare that they have no competing interests.

\section{Acknowledgments}

This work is supported by NSFC 61571282.

\section{References}

[1] E. Ghafari, A. Fuchs, D. Eblenkamp, and D. N. Aloi, "A vehicular rooftop, shark-fin, multiband antenna for the GPS/ 
LTE/Cellular/DSRC systems," in Proceedings of the IEEE-APS Topical Conference on Antennas and Propagation in Wireless Communications (APWC '14), pp. 237-240, 2014.

[2] T. Ijiguchi, D. Kanemoto, K. Yoshitomi et al., "Circularly polarized one-sided directional slot antenna with reflector metal for 5.8-GHz DSRC operations," IEEE Antennas and Wireless Propagation Letters, vol. 13, pp. 778-781, 2014.

[3] D. N. Aloi, M. Possa, A. Barghouti, J. Tlusty, and M. Sharawi, "Printed DSRC antennas for enhanced gain coverage towards front and rear of vehicle for automotive applications," in Proceedings of the IEEE 2014 Topical Conference on Antennas and Propagation in Wireless Communications (APWC '14), pp. 349-352, IEEE-APS, Palm Beach, Aruba, August 2014.

[4] J. K. Lee and K. Chang, "Dual-band switched beam array fed by dual-band Butler matrix," Electronics Letters, vol. 47, no. 21, pp. 1164-1165, 2011.

[5] A. M. El-Tager and M. A. Eleiwa, "Design and implementation of a smart antenna using butler matrix for ISM-band," in Proceedings of the Progress in Electromagnetics Research Symposium, pp. 571-575, Beijing, China, March 2009.

[6] S. Y. Zheng, S. H. Yeung, W. S. Chan, K. F. Man, S. H. Leung, and Q. Xue, "Dual-band rectangular patch hybrid coupler," IEEE Transactions on Microwave Theory and Techniques, vol. 56, no. 7, pp. 1721-1728, 2008.

[7] Y. Li, S. Sun, F. Yang, and L. J. Jiang, "Design of dual-band slotted patch hybrid couplers based on PSO algorithm," Journal of Electromagnetic Waves and Applications, vol. 25, no. 17-18, pp. 2409-2419, 2011.

[8] S. Y. Zheng, Y. Wu, Y. Li, Y. Liu, and Y. Long, "Dual-band hybrid coupler with arbitrary power division ratios over the two bands," IEEE Transactions on Components, Packaging and Manufacturing Technology, vol. 4, no. 8, pp. 1347-1358, 2014.

[9] Y. Li, S. Sun, and F. Yang, "Dual-band hybrid patch coupler with embedded spiral open stubs," in Proceedings of the Asia-Pacific Microwave Conference (APMC '12), pp. 169-171, December 2012.

[10] S. Sun and L. Zhu, "Miniaturised patch hybrid couplers using asymmetrically loaded cross slots," IET Microwaves, Antennas and Propagation, vol. 4, no. 9, pp. 1427-1433, 2010.

[11] M. R. Vidyalakshmi and S. Raghavan, "A CAD model of triangular split ring resonator based on equivalent circuit approach," in Proceedings of the Applied Electromagnetics Conference, URSI Commission B Meeting (AEMC '09), pp. 1-4, December 2009.

[12] M. R. Vidyalakshmi, B. Rekha, S. Raghavan, and P. H. Rao, "Left-handed CTSRR-slot pair loaded microstrip transmission line," in Proceedings of the IEEE Applied Electromagnetics Conference (AEMC '11), pp. 1-4, Kolkata, India, December 2011.

[13] L. Zhu, P.-M. Wecowski, and K. Wu, "New planar dual-mode filter using cross-slotted patch resonator for simultaneous size and loss reduction," IEEE Transactions on Microwave Theory and Techniques, vol. 47, no. 5, pp. 650-654, 1999. 


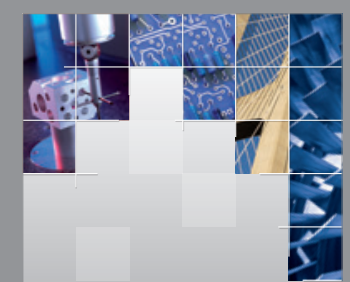

\section{Enfincering}
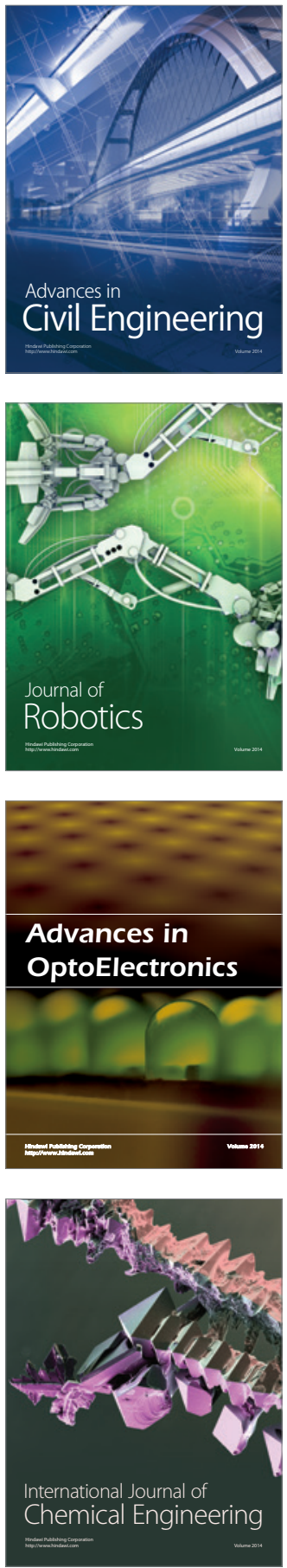

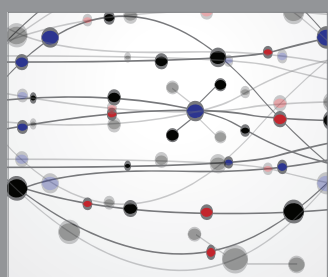

The Scientific World Journal

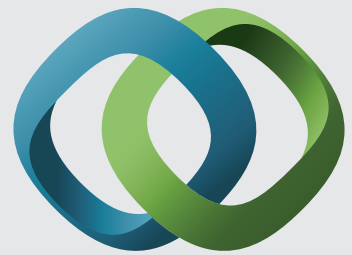

\section{Hindawi}

Submit your manuscripts at

https://www.hindawi.com
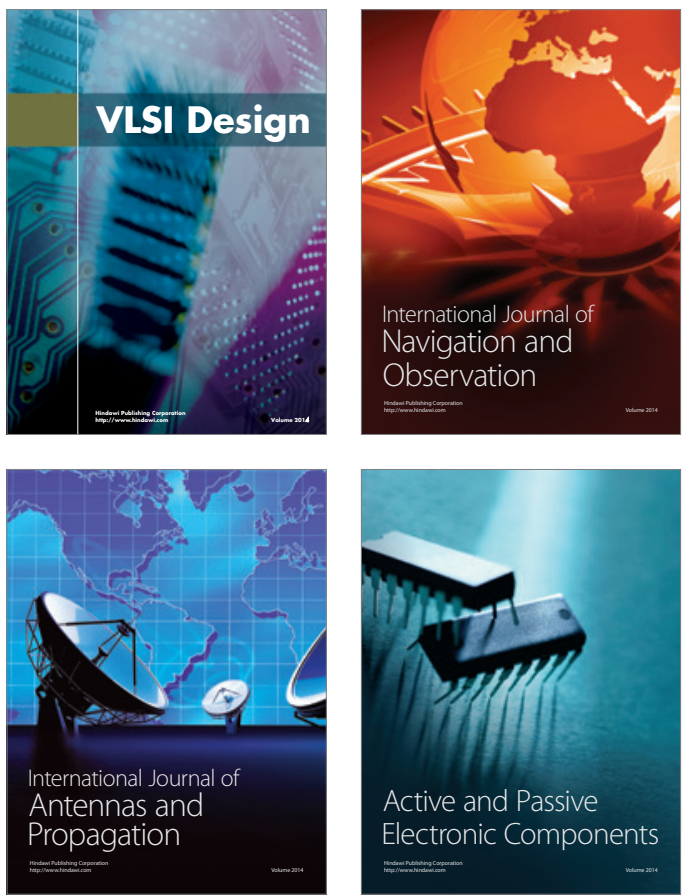
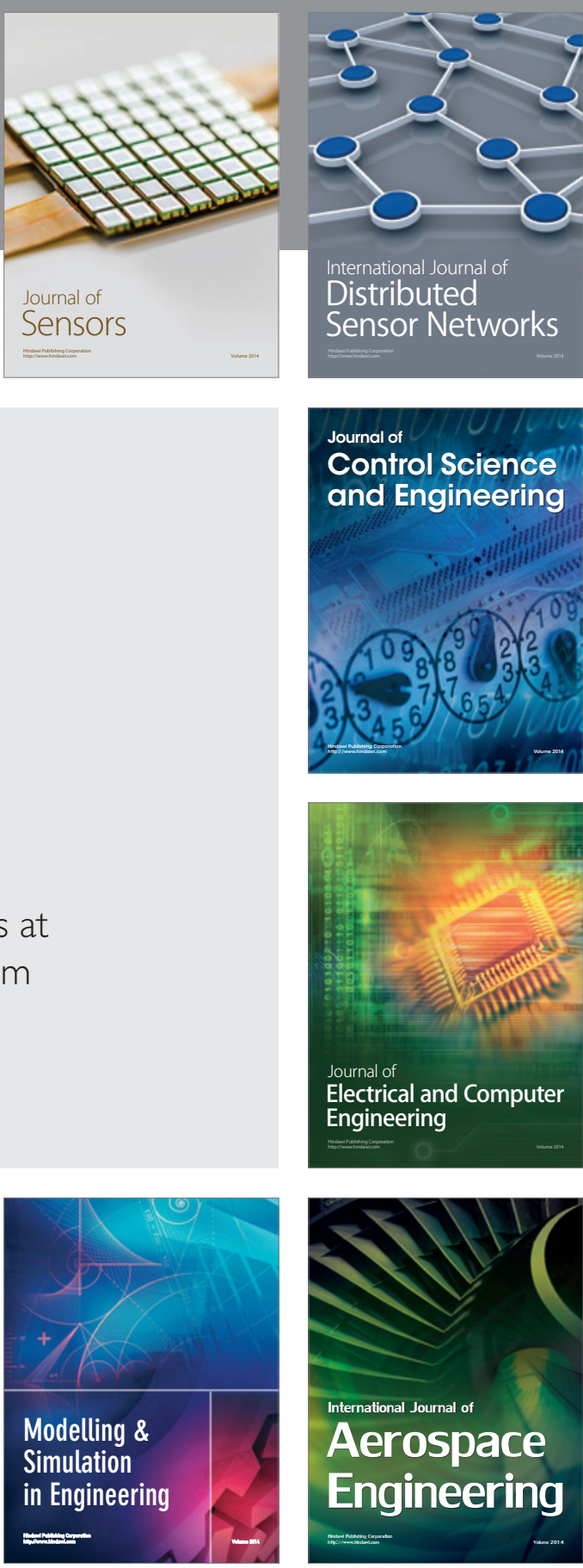

International Journal of

Distributed

Sensor Networks

$-$

Joumal of

Control Science

and Engineering
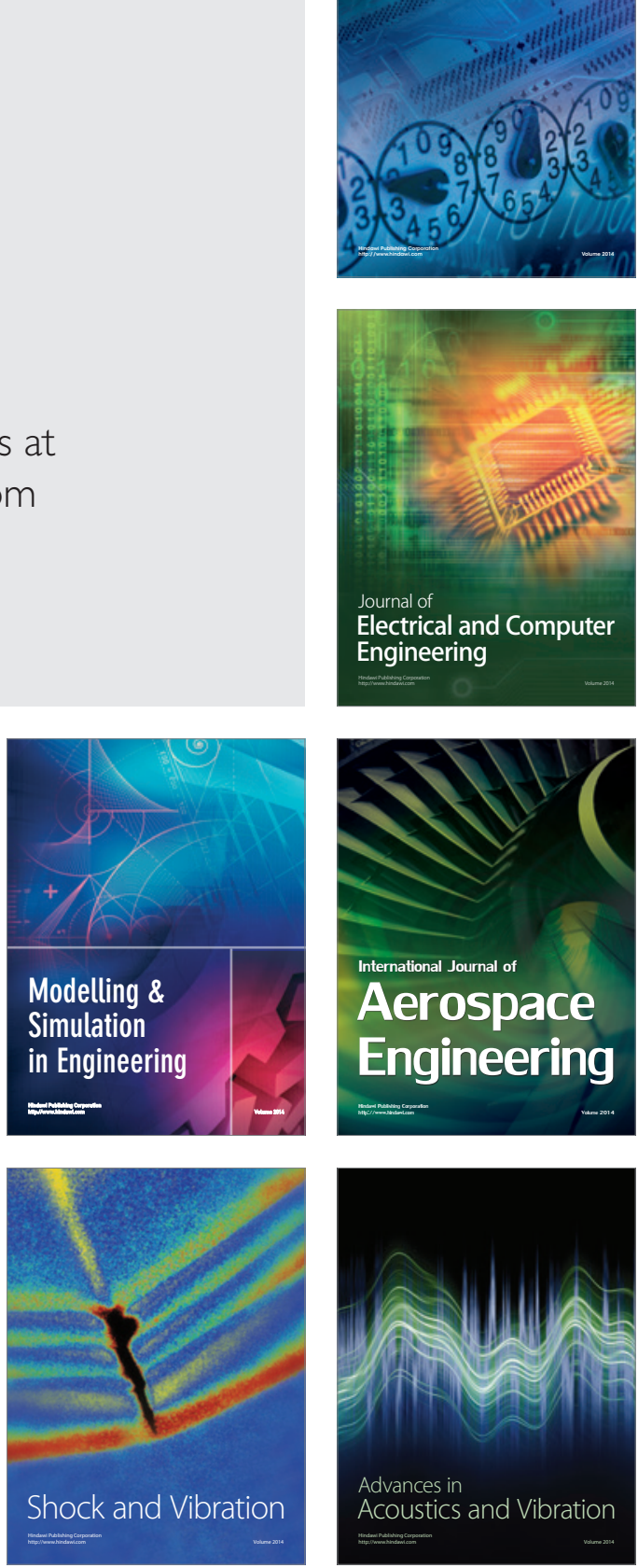